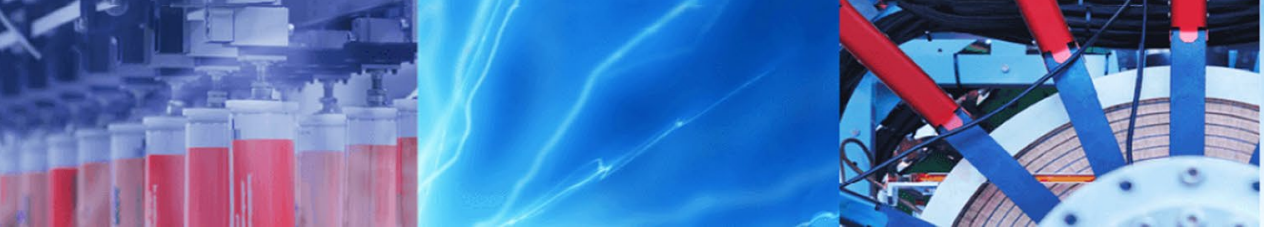

Research Article

\title{
Synthesis and characterization of $\mathrm{a}-\mathrm{Fe}_{2} \mathrm{O}_{3} / \mathrm{Y}^{-}-\mathrm{Fe}_{2} \mathrm{O}_{3}$-nanoparticles from recyclable electro-coagulated sludge: insights and predictions for different application
}

\author{
Tadele Assefa Aragaw $^{1}$ (D) . Belete Asefa Aragaw² ${ }^{2}$
}

Received: 29 April 2020 / Accepted: 17 September 2020 / Published online: 1 October 2020

(c) Springer Nature Switzerland AG 2020

\begin{abstract}
This research work reports on the synthesis and characterization of iron oxide nanoparticles from sludge. Precipitates generated from the electro-coagulation process were collected, size reduced, beneficiated, and thermally treated in an inert atmosphere to form iron oxide nanoparticles. Structural, surface, and optical properties of raw and thermally treated sludge were examined using XRD, SEM, FTIR, UV/Vis, TGA/DTA, and Zeta Potential. The X-ray diffraction pattern confirmed that as the sludge is annealed at a temperature of $100,300,500$, and $800^{\circ} \mathrm{C}$, the phase transformed to goethite, magnetite, maghemite, and hematite respectively. Pure hematite weere formed at the highest temperature. The crystallite size of hematite nanoparticle was calculated using the two most intense diffraction peaks and found to be about $30.4 \mathrm{~nm}$ at $800{ }^{\circ} \mathrm{C}$ and $28.3 \mathrm{~nm}$ at $500^{\circ} \mathrm{C}$. The SEM micrograph for heat-treated powered has an irregular shape with rough and porous surfaces leading to the best adsorptive feature. The optical band gap was found to be $2.06,1.98$, and $2.00 \mathrm{eV}$ for $300^{\circ} \mathrm{C}, 500{ }^{\circ} \mathrm{C}$, and $800^{\circ} \mathrm{C}$ heat-treated samples respectively. These findings can be an input to the industrialists and environmentalists that controlled sludge recycling mechanisms during wastewater treatment is beneficial in terms of cost and sustainability. Furthermore, an integrated wastewater treatment system with resource recycling technology at the initial stage of the installation could be made.
\end{abstract}

Tadele Assefa Aragaw, taaaad82@gmail.com | ${ }^{1}$ Faculty of Chemical and Food Engineering, Bahir Dar Institute of Technology, Bahir Dar University, Bahir Dar, Ethiopia. ${ }^{2}$ Department of Chemistry, College of Natural Science, Bahir Dar University, Bahir Dar, Ethiopia. 


\section{Graphic abstract}

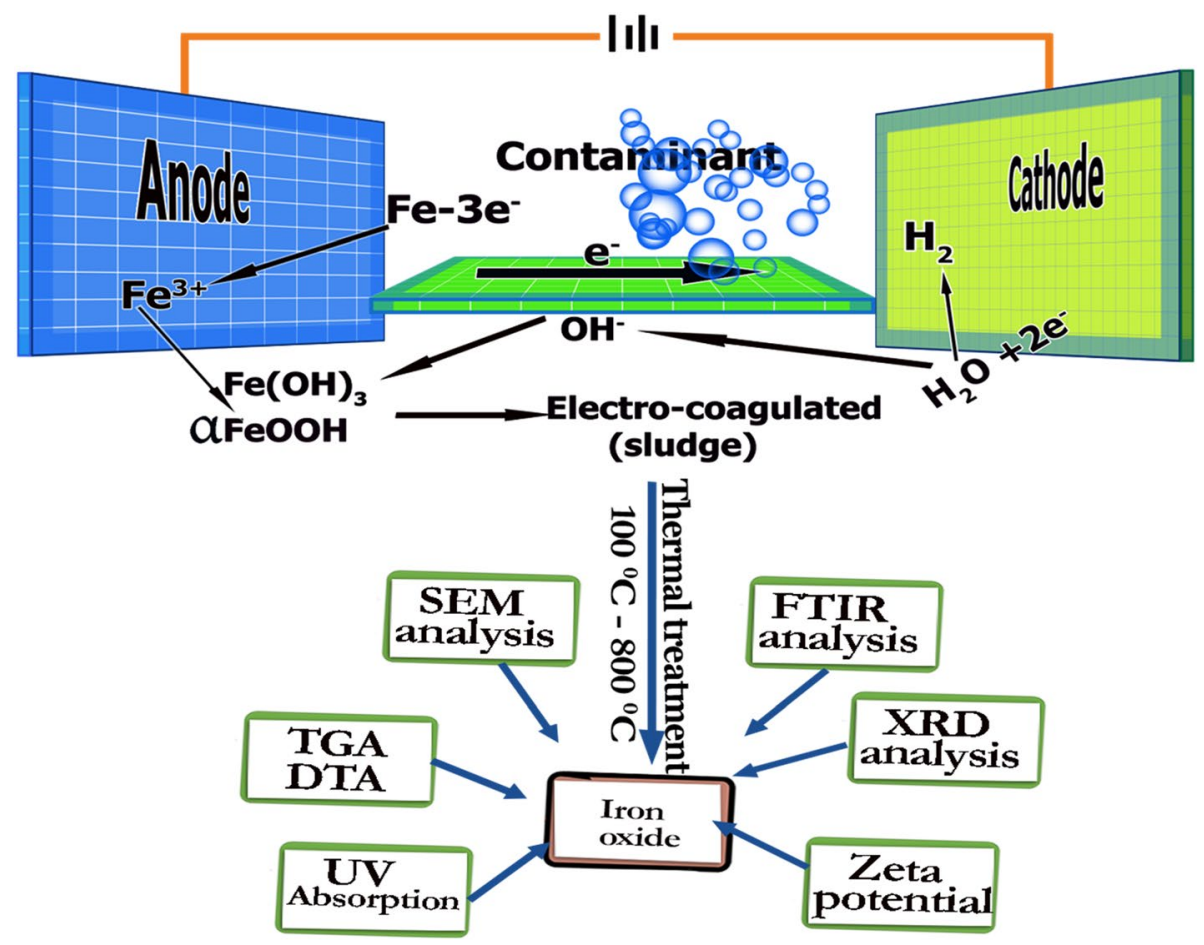

Keywords Electro-coagulated sludge $\cdot a-\mathrm{FeO}(\mathrm{OH}) \cdot a-\mathrm{Fe}_{2} \mathrm{O}_{3} \cdot \gamma-\mathrm{Fe}_{2} \mathrm{O}_{3} \cdot$ Heat treatment $\cdot$ Nanoparticle

\section{Introduction}

Nowadays, an important paradigm shift is necessary at multiple levels to advance sustainable environmental management services toward a circular economy in which wastewater and sludge from it are considered a valuable resource rather than a liability. Like that of energy, clean water, fertilizers, and nutrients can be extracted from wastewater, valuable materials from the waste sludge can be recycled and prepared for different application which is helpful to achieve the sustainable development goals (SDGs). Initiatives in the researchers, the industrials, policymakers, and governments are critical to address the sludge from wastewater treatment plants challenge and raise awareness about its potential resource. Especially, iron oxide and hydroxide contained sludge is the main constituent from electroplating, iron metallurgy, electrocoagulation, and the like processing factory wastewater treatment plants.

The main by-products of wastewater treatment with electrocoagulation process using iron electrodes are ferrous hydroxide, ferric hydroxide, and iron oxyhydroxide [1]. Those different iron hydroxide species generation persuades electrophoretic clustering of negatively charged colloids in the nearby positively charged iron electrodes which form polyatomic surface complexation within the electrolyte, electric current and electrode interaction [2, 3] Organic contaminants having active functional groups adsorbed by iron hydroxide precipitate with in situ coagulation system by a weak Van der Waals forces. The precipitates, which are formed with electrochemistry principle, have the capability of removing the organic contaminants in such a way that iron hydroxide has driven electrostatic interaction by adsorbing to the surface of the precipitate products [4].

Internal interaction with other dissolved contaminants; like azo dyes which are a major contaminant in textile effluent, inorganic ionic compounds, and metal ions also have a contribution in situ electrocoagulation processes. As a result, heavy metals and other elements contained in the effluents [5] can take place hydrolysis and redox reaction to form coagulated flocs through a complicated 
electrochemical and physicochemical interaction in the process. In addition to the conventional hydroxides of iron, ox-hydroxides of iron can have a chance to be formed and removed from the process as goethite $\mathrm{a}-\mathrm{FeOOH}$ and lepidocrocite $y-\mathrm{FeOOH}$ which can be used as a source for iron oxides production iron oxides like hematite, maghemite, and magnetite $[5,6]$.

The formation of different iron oxide nanoparticles through dehydration and thermal oxidation of iron hydroxides $/ \mathrm{Fe}_{3} \mathrm{O}_{4}$ are processed with a range of temperature phase interchanges between magnetite $\left(\mathrm{Fe}_{3} \mathrm{O}_{4}\right)$-maghemite- $\left(\gamma-\mathrm{Fe}_{2} \mathrm{O}_{3}\right)$-hematite $\left(\alpha-\mathrm{Fe}_{2} \mathrm{O}_{3}\right)$ which can be determined with X-ray diffraction techniques $[7,8]$. In the thermal treatment with a range of temperatures, magnetite can undergo oxidation and forms stable hematite $\mathrm{a}-\mathrm{Fe}_{2} \mathrm{O}_{3}$ $[9,10]$. Magnetite can be transformed first to $\mathrm{Y}-\mathrm{Fe}_{2} \mathrm{O}_{3}$ from 200 to $400{ }^{\circ} \mathrm{C}$, and with a subsequence, the temperature can be transformed to a- $\mathrm{Fe}_{2} \mathrm{O}_{3}$ starting from $550{ }^{\circ} \mathrm{C}$ and above. Thus, thermal treatment with a certain range affects a stepwise formation of maghemite and hematite family of iron oxides. With increasing the temperature, the oxidative transformation of magnetite into hematite favors and quantity of hematite dominates at high temperatures.

Iron oxides in a nanoparticle (magnetite and hematite) form have a wide-ranging usage for commercial as well as industrial applications through technological advancement, due to their pigmented feature, especially it has wide application in pigment manufacturing technology $[11,12]$. Iron oxide nanoparticles enormous for biomedical applications due to their unique magnetic properties, nontoxicity, and biodegradability, superparamagnetic iron oxide nanoparticles, targeted drug delivery, therapy, and cell separation [13].

Most of the time, iron oxide nanoparticles having a magnetic nature, hematite and maghemite, have many applications for the industry and medicinal purpose as a catalyst ferrofluids, magnetic ink, and footage media [12]. Maghemite and hematite are excellent materials due to having low manufacturing costs and also are stable in the acidic solution media which can offer photocatalysis reaction, water-splitting technology, and gas sensors [14-17]

In the environmental remediation point of view, iron oxides carryout promising results as a catalyst and adsorbent. Adsorption of organic matter in the wastewater stream on magnetic powdered activated carbon was studied by Lompe et al. [18]. Also the adsorption potentials of electro-coagulated sludge, raw, and produced iron oxide nanoparticles after thermal treatment were investigated for direct red 28 dye [19]. The synthesis and properties of iron oxides and the raw EC sludge adsorbent for the removal of direct red dye are described in detail including its isotherm and kinetics phenomenon. The best removal efficiency was recorded with alternating various parameters like solution $\mathrm{pH}$, temperature, adsorption time, adsorbent dosage, and dye concentration. Another study by Mousavi et al. [20] of iron oxides and its modification with different materials for wastewater treatment is examined.

Recovery and investigating the surface and structural properties of electro-coagulated sludge from textile wastewater treatment plants which can be used for the different applications have promising advantages to the total sustainability of the environment in such a way that sludge waste management in the future and resource utilization. The present study focuses on the wet and thermal treatment mechanism of electro-coagulated sludge through a range of temperatures to produce valuable iron oxide nanoparticles. Also, chemical, surface, and structural characteristics of the raw EC sludge and produced iron oxide were investigated using FTIR, UV absorption, XRD, TGA/DTA, and SEM analytical techniques. This research work aims to study the recycling of EC sludge and surface and structural characterization of iron oxide nanoparticles through a range of temperatures.

\section{Materials and methods}

\subsection{Overview of the electrochemical process}

The electrocoagulation processes of a textile wastewater treatment plant have the so-called cascade electrochemical reactor. The system has two compartments as a coaxial flow electrochemical reactor, comprising of a central galvanized platinum as cathode and iron as an anode (plate iron sheet) having an anode-to-cathode surface spacing and electrode gaps.

The inlet and outlet of the system confirmed as a uniform fluid flow in the cascade reactor through the chamber as per the manufacturer's design and flushing of formed gases and solids are removed manually with skilled operators. Before the electrocoagulation unit processes, the textile effluent has a grit chamber unit process to remove the coarse particles and is homogenized from the equalization tank to neutralize the basic media and make the effluent suitable to the reactor. Concentrated sulfuric acid is added to the wastewater at the equalization tank to form a neutral environment to improve electrooxidation processes and also can be able to dissolve the suspended materials which were not trapped at the grit chamber. The treatment system is a continuous having a recirculation system by one-third of the inlet volume at the manufacturer's design flow rate of $20-25 \mathrm{~m}^{3} \mathrm{~h}^{-1}$ through the electrochemical reactor for the electrolyte (wastewater) TDS concentration above $500 \mathrm{mg} / \mathrm{L}$. The cascade reactor is operated in galvanostatic mode at the $20-30 \mathrm{Amp} / \mathrm{s}$ 
current density proportional to the inlet volumes of the wastewater with continuous treatment time (for $1 \mathrm{~m}^{3} \mathrm{~h}^{-1}$ ) in a pH range of 6-7 at ambient temperature. The DC voltage is automatically changed based on the current density adjustment

\subsection{Electrocoagulation mechanisms}

The electrocoagulation $(E C)$ processes is an electrochemical reaction which can produce coagulants and removing the suspended, colloidal, and dissolved materials for wastewater treatment. In the EC processes, the generation of coagulants by dissolution anodic electrodes with simultaneous formation of hydroxyl ions and hydrogen gas from the cathodic electrode. In the EC process, iron hydroxide and/or polyhydroxide precipitates are produced [21]. Some the dissolved organic impurities have been adsorbed on to the iron hydroxide and/or polyhydroxide precipitates and can be removed by beneficiation, and the thermal treatment [22]. The EC process generates three layers of iron hydroxide and/or iron oxide precipitates in different states of oxidation as shown in Eqs. 1-4 [21].

$2 \mathrm{Fe}+\mathrm{O}_{2}+\mathrm{H}_{2} \mathrm{O}=2 \mathrm{Fe}(\mathrm{OH})_{2}$

$\mathrm{Fe}(\mathrm{OH})_{2}+(\mathrm{n}-1) \mathrm{H}_{2} \mathrm{O}=\mathrm{FeO} \cdot \mathrm{nH}_{2} \mathrm{O}$

$4 \mathrm{Fe}(\mathrm{OH})_{2}+\mathrm{O}_{2}=2 \mathrm{Fe}_{2} \mathrm{O}_{3} \cdot \mathrm{H}_{2} \mathrm{O}+2 \mathrm{H}_{2} \mathrm{O}$

$\mathrm{Fe}_{2} \mathrm{O}_{3}+\mathrm{FeO}=\mathrm{Fe}_{3} \mathrm{O}_{4}$

\subsection{Sample collection and physical treatment}

Sludge samples were collected from Bahir Dar Textile factory wastewater treatment plant, Bahir Dar, Ethiopia. It was dried with an oven at $70{ }^{\circ} \mathrm{C}$, ground and milled using a jaw crusher and disc mill. The desired product was used for soaking and oversize products have been returned to the crusher. For the separation of desired powered from grease, soluble salts, organics, the soaking was conducted. The powdered sludge was dispersed in de-ionized water for $24 \mathrm{~h}$ and bunged to separate all floatable oils, specks of dust, and dissolved solid particles. With decanting the supernatant, the slurry was washed until the unstable suspended particle removed. The suspension after wet treatment was dried at $70^{\circ} \mathrm{C}$ to remove absorbed water, again dried, ground and milled to make fine powder for thermal treatment.

\subsection{Thermal treatment}

The high-temperature oxidative transformation of iron hydroxides $/ \mathrm{Fe}_{3} \mathrm{O}_{4}$ has followed a range of temperaturedependent phase interchanges from maghemite to hematite [8]. The anhydrous product from the physically treated EC sludge powered was sampled to a crucible cup and placed inside a muffled furnace. Nitrogen gas was supplied from external sources to the furnace with a flow rate of $100 \mathrm{~min}^{-1}$ for $20 \mathrm{~min}$ to make an inert atmosphere and was thermally treated with constant nitrogen flow at $10 \mathrm{~min}^{-1}$ for $3 \mathrm{~h}$ to remove organics from the sludge and oxidative transformations to hematite type of iron oxide nanoparticle. At each temperature $\left(100,300,500\right.$, and $\left.800^{\circ} \mathrm{C}\right)$, the same treatment conditions and time were maintained. The mass loss as the organic carbon content of the dehydration from the sludge was determined by classical gravimetric analytical techniques and was recorded as less than $10 \%$.

\subsection{Surface and structural characterization}

FTIR (JASCO 6600 typeA) spectrophotometer was used to determine the functional groups for raw and thermally treated (at 300,500 , and $800{ }^{\circ} \mathrm{C}$ ) EC sludge. The analysis was done at a wavenumber range of $400-4000 \mathrm{~cm}^{-1}$. The powder sample with $\mathrm{KBr}$ was grounded uniformly using mortar and pestle and pelletized. Raw and thermally treated $\left(300,500\right.$, and $\left.800{ }^{\circ} \mathrm{C}\right) \mathrm{EC}$ sludge were used for functional group determination. X-ray diffraction, XRD, is a method that can be used to detect the crystalline phases of the materials in it and for quantitative analysis. Particularly, it is used due to the superior highlighting of the dimensional atomic structure that has a direct implication on the characteristics of the nanomaterial. The crystalline and phase interchange were examined for both the raw and thermally treated (at $100,300,500$, and $800^{\circ} \mathrm{C}$ ) $E C$ sludge, and the diffraction patterns were measured using XRD (SHIMADZU, MAXima_X XRD-7000) with CuK radiation. $X R D$ diffractograms were obtained between the X-ray intensity on the ordinate and the Bragg angle, $\theta$, on the abscissa were performed on a $\theta-2 \theta$ angle range between $10^{\circ}$ and $80^{\circ}$ through continuous scanning at a step size of $0.02^{\circ}$ with a counting time of $1 \mathrm{~s}$ per step with a scan speed of $0.054(\%)$ at a $40 \mathrm{kV}$ voltage and $30 \mathrm{~mA}$ current intensity with divergence slit: $1.0\left({ }^{\circ}\right)$, scatter slit: 1.0 $\left({ }^{\circ}\right)$, receiving slit: $0.30(\mathrm{~mm})$. The surface morphology of the raw, as well as thermally treated, $500^{\circ} \mathrm{C}$, EC sludge, were examined using scanning electron-microscope, Inspect ${ }^{\mathrm{TM}}$ Scanning Electron Microscope, SEM (INSPECT F50) with different magnification and scale bar. Zeta potential and Electrophoretic mobility measurements were done using a zeta potential meter (Malvern Zetasizer Nano ZS series) 
at different $\mathrm{pH}$ values to determine the surface charge nature. The values were recorded $2,4,6,8,10,11$, and 12 $\mathrm{pH}$ values. It determines the electrophoretic mobility of the particles automatically in the powered and converts

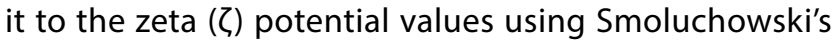
Eq. 5 [23].

$v_{E}=4 \pi \varepsilon_{0} \varepsilon_{r} \zeta 6 \pi \mu(1+\kappa r)$

where $\varepsilon_{0}$ and $\varepsilon_{r}$ are the relative dielectric constant and the electrical permittivity of a vacuum respectively, $\mu$ is the solution viscosity, $r$ is the particle radius and $\mathrm{k}=\left(2 \mathrm{n}_{0} \mathrm{z}^{2} \mathrm{e}^{2} /\right.$ $\left.\varepsilon_{r} \varepsilon_{0} k_{B} T\right)^{1 / 2}$ is the Debye-Hückel parameter, $n_{0}$ is the bulk ionic concentration, $z$ is the valence of the ion, $e$ is the charge of an electron, $\mathrm{k}_{\mathrm{B}}$ is the Boltzmann constant, and $T$ is the absolute temperature.

\subsection{Thermal analysis}

The raw electro-coagulated sludge mass loss by thermogravimeter, TGA was analyzed simultaneously with the phase transformations analysis using differential thermal analysis, DTA, through ATAT2012 equipment. The measurements were carried out from room temperature up to $1000^{\circ} \mathrm{C}$ temperature ranges with air atmosphere in a flow rate of 10 and $20 \mathrm{~mL} / \mathrm{min}$ on a sample mass of $15 \mathrm{mg}$. The thermogravimeter analyzed thermal accuracy and stability was calibrated by heating indium (melting point $=156.6^{\circ} \mathrm{C}$ ) as a standard at 10,15 , and $20^{\circ} \mathrm{C} / \mathrm{min}$. The analysis was conducted using TGA-DTA emphasized their thermal stability and the mass loss through two curves simultaneously plotted based on the temperature profile.

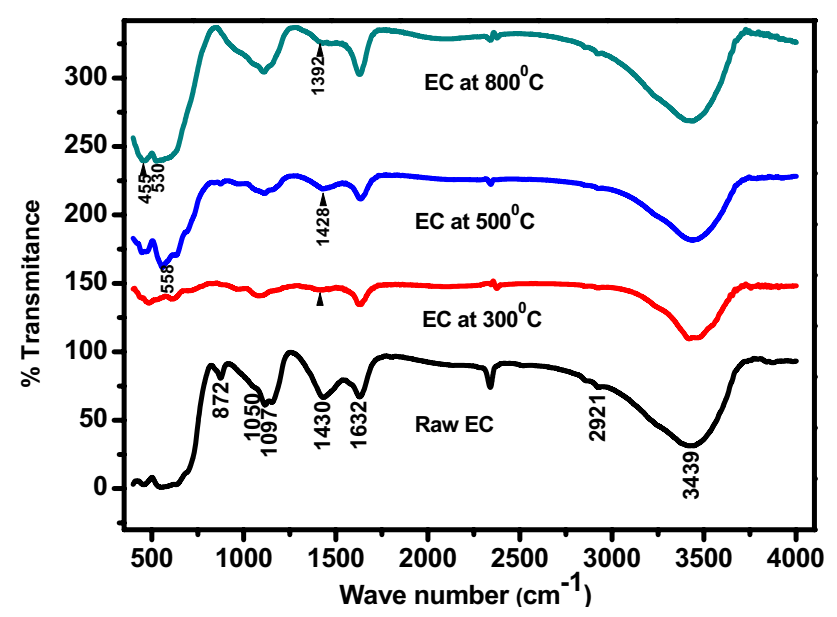

Fig. 1 FTIR spectral analysis of raw and thermal treated at (300, 500 , and $800^{\circ} \mathrm{C}$ ) EC sludge

\subsection{Optical properties}

UV-visible diffusion reflectance is important to determine the optical properties and the bandgap of the material. The diffusion reflectance spectra of the raw and thermally treated $\left(300,500\right.$, and $\left.800^{\circ} \mathrm{C}\right)$ electro-coagulated sludge was determined. The spectra was acquired using color-eye spectrophotometer (Color-Eye3100). Powdered electrocoagulated samples were pressed by hand with stainless steel washer for suitable pellet formation. The formed thick pellet with a support of the pellet holding materials were placed. $\mathrm{BaSO}_{4}$ integrating sphere as $100 \%$ reflectance white standard were used. The Diffuse reflectance spectra were recorded from 400 to $700 \mathrm{~nm}$.

\section{Result and discussion}

\subsection{FTIR spectral analysis}

FTIR spectra of raw and thermally treated $(300,500$, and $800^{\circ} \mathrm{C}$ ) EC sludge with a scanning range of $4000-400 \mathrm{~cm}^{-1}$ are depicted in Fig. 1. Bands appearing at 3439 and $2921 \mathrm{~cm}^{-1}$ are for the stretching vibrations of $\mathrm{O}-\mathrm{H}$ which is assigned to surface $\mathrm{OH}$ groups of ferric oxyhydroxide and iron oxide and $\mathrm{C}-\mathrm{H}$ stretching respectively. Also, the peaks at $1632,1430,1097$ and $872 \mathrm{~cm}^{-1}$ are for the asymmetric and symmetric vibration in $\mathrm{C}=\mathrm{O}$ stretching in the carboxyl functional group [24], $\mathrm{N}=\mathrm{N}$ stretching bands, $\mathrm{C}-\mathrm{O}$ stretching and $\mathrm{N}-\mathrm{H}$ deformation in the amines respectively from the raw EC sludge. The absorption peaks at $3439 \mathrm{~cm}^{-1}$ and $1632 \mathrm{~cm}^{-1}$ after thermal treatment is also attributed to the water of hydration. The bending frequency of surface hydroxyl group was observed at $1392 \mathrm{~cm}^{-1}$ and increases its peak intensity as the temperature increases which are similar to previous reports [25]. A small peak appeared at $881 \mathrm{~cm}^{-1}$ and $1050 \mathrm{~cm}^{-1}$ in the raw EC sludge were disappeared after thermal treatment. This is due to the adsorbed carboxyl and amine functional group in the dye molecule thermal decomposition. Most Azo $\mathrm{N}=\mathrm{N}$ stretching bands occur between 1580 and $1400 \mathrm{~cm}^{-1}$ which are shown in raw EC but disappeared from thermally treated. Also absorption bands at $3424 \mathrm{~cm}^{-1}$ which may be attributed to the $-\mathrm{NH}_{2}$ group, which overlaps with the stretching vibration of the $\mathrm{OH}$ groups. Also, the presence of the peak located around $2900 \mathrm{~cm}^{-1}$ corresponds to $\mathrm{C}-\mathrm{H}$ vibrations in the raw $\mathrm{EC}$ sludge tells that there is adsorbed organic carbon from the sludge but disappeared after thermal treatment $[26,27]$. The bands appearing from 450 to $650 \mathrm{~cm}^{-1}$ belongs to the $\mathrm{Fe}-\mathrm{O}$ stretching vibration of $\mathrm{Fe}_{2} \mathrm{O}_{3}$ [28], indicating that iron oxide nanoparticles are formed after thermal treatment of magnetite and iron hydroxides. The band corresponding to $\mathrm{Fe}-\mathrm{O}$ stretching 
mode of a- $\mathrm{Fe}_{2} \mathrm{O}_{3}$ is shown at $576 \mathrm{~cm}^{-1}$ having a sharp (high) intensity after thermal treatment at 500 and $800^{\circ} \mathrm{C}$ suggesting that the $\mathrm{a}-\mathrm{FeOOH} / \mathrm{Fe}_{3} \mathrm{O}_{4}$ have undergone an oxidative transformation to maghemite and hematite. The peaks at about 455 for the samples treated at $500^{\circ} \mathrm{C}$ and $800^{\circ} \mathrm{C}$, and 558 and 530 for the samples treated at $500^{\circ} \mathrm{C}$ and $800^{\circ} \mathrm{C}$ respectively, are assigned $\mathrm{Fe}-\mathrm{O}$ vibrations which are characteristic vibrations bands at of intrinsic $\mathrm{a}-\mathrm{Fe}_{2} \mathrm{O}_{3}$ nanostructure $[29,30]$. According to Chernyshova et al. the bands of hematite nanoparticle can vary within $662-526 \mathrm{~cm}^{-1}$ and $494-437 \mathrm{~cm}^{-1}$ ranges depending on the particle size and presence of impurities [31]. For example, Mohammed et al. [32] reported that Fe-O stretching vibrations are shifted toward lower wavenumber side up to $\mathrm{Zn} 4 \%$ and then shift to higher wavenumber for $\mathrm{Zn} 6 \%$ due to variation in cation-oxygen bond length. The band appearing at $1097 \mathrm{~cm}^{-1}$ is typically metal hydroxyl (M-OH) stretching vibration from raw EC sludge but disappeared after thermal treatment due to its transformation to iron oxide nanoparticles [33,34]. Thus, thermal treatment of the $\mathrm{EC}$ sludge is important for the productions of the most valuable iron oxide, $\gamma$ - $\mathrm{Fe}_{2} \mathrm{O}_{3} / a-\mathrm{Fe}_{2} \mathrm{O}_{3}$-nanoparticles from iron hydroxide/oxy-hydroxide and magnetite. According to the study by Ovcharenko et al. the formation of O-defect on $\mathrm{a}-\mathrm{Fe}_{2} \mathrm{O}_{3}$ during heat treatment at $800^{\circ} \mathrm{C}$ leads to dissociative water adsorption at oxygen vacancy sites where the $\mathrm{OH}$-fills the vacancy position [35]. This could be the reason for intense $\mathrm{OH}$ bands of $\mathrm{a}-\mathrm{Fe}_{2} \mathrm{O}_{3}$.

\subsection{X-ray diffraction analysis}

The X-ray diffraction patterns recorded for electro-coagulated $(E C)$ sludge from electrochemical unit processes

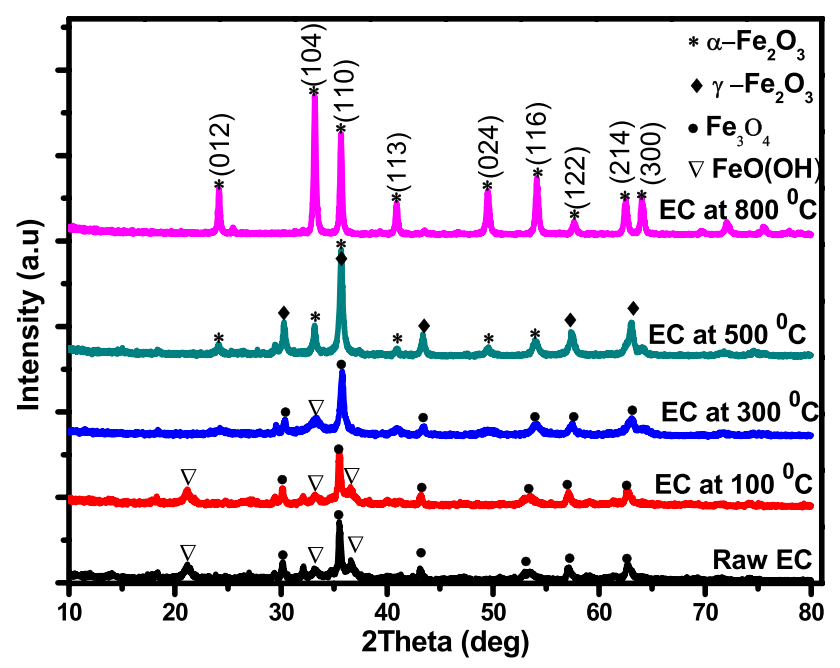

Fig. 2 X-ray diffraction pattern of raw and thermally treated (100$800^{\circ} \mathrm{C}$ ) EC sludge of textile wastewater treatment plants are depicted in Fig. 2. The major diffraction patterns corresponding to $\mathrm{a}-\mathrm{FeOOH}$ (goethite) are observed at $2 \theta=21.2^{\circ}, 33.2^{\circ}$, and $36.5^{\circ}$ whereas peaks at $18.4,30.2,35.6,43.2,53.5,57.2$, and 62.7 are due to $\mathrm{Fe}_{3} \mathrm{O}_{4}$ (magnetite) phase in raw and thermally treated at $100^{\circ} \mathrm{C} \mathrm{EC}$ sludge. The formation of goethite (orthorhombic) and magnetite (cubic) phases are in agreement with ICSD reference code 01-081-0462 and 01-089-3854 respectively. The goethite phase disappeared when thermally treated with temperature $300^{\circ} \mathrm{C}$ and above. This is due to the transformation of a-FeOOH to magnetite, maghemite, and hematite. At $300^{\circ} \mathrm{C}$, the XRD pattern displays major characteristic peaks due to magnetite situated at $2 \theta$ values of $30.2^{\circ}, 33.4^{\circ}, 35.7^{\circ}, 43.2^{\circ}, 53.5^{\circ}$, $57.1^{\circ}$, and $62.8^{\circ}$ in agreement with ICSD reference code 01-089-3854 for cubic magnetite crystal. All the peaks are higher angle shifted to the reference. This is due to the oxidation of $\mathrm{Fe}^{2+}-\mathrm{Fe}^{3+}$ in the magnetite structure. Magnetite contains both $\mathrm{Fe}^{2+}$ and $\mathrm{Fe}^{3}$ with $1: 2$ ratio $\left(\mathrm{Fe}^{2+}: \mathrm{Fe}^{3}\right)$. During heat treatment of magnetite, some of the $\mathrm{Fe}^{2+}$ could be oxidized to $\mathrm{Fe}^{3+}$. Due to the smaller ionic radius of $\mathrm{Fe}^{3+}$ compared to $\mathrm{Fe}^{2+}$, the crystal exhibit lattice contraction which results from a higher angle shift in diffraction measurement. At $500^{\circ} \mathrm{C}$, the magnetite phase disappeared as a result of its oxidative transformation to the $\mathrm{Fe}_{2} \mathrm{O}_{3}$ phase. Diffraction angles at 30.3, 35.6, 43.5, 54.0, 57.4, and 63.1 are due to maghemite $\left(\gamma-\mathrm{Fe}_{2} \mathrm{O}_{3}\right)$ and $33.2,35.6,49.5$, and 54.1 are due to hematite $\left(\mathrm{a}-\mathrm{Fe}_{2} \mathrm{O}_{3}\right)$ phase according to ICSD reference code 00-025-1402 and 01-073-2234 respectively. Finally at $800^{\circ} \mathrm{C}$ maghemite is converted and a pure rhombohedral hematite phase is formed with no other impurities exhibiting sharp and strong peaks. All the peaks at $24.2^{\circ}, 33.3^{\circ}, 35.7^{\circ}, 41.0^{\circ}, 49.6^{\circ}, 54.1^{\circ}, 62.4^{\circ}, 64.1^{\circ}$ match well with hematite (ICSD reference code 01-079-1741). This shows the highly crystalline nature of the material formed which is one of the requirements for optoelectrical and catalysis applications.

A similar study was reported by Cho et al. [36]. The diffraction line $2 \theta=30.2$ and $43^{\circ}$ from the raw to heat-treated up to $500^{\circ} \mathrm{C}$ indicates the inverse spinel iron ferrite $\left(\mathrm{Fe}_{3} \mathrm{O}_{4}\right)$ structure and thermally treated at $700{ }^{\circ} \mathrm{C}$ disappeared which suggests that the no ferrites can exist at high temperature $[37,38]$. This suggests that ferrite is completely transformed into hematite. The XRD diffractograms in Fig. 2 obtained after thermal treatment with a range of temperatures illustrate that iron oxy-hydroxide and goethite $(\mathrm{FeOOH})$ phases disappeared after $300^{\circ} \mathrm{C}$ and completely transformed to maghemite and hematite at $500^{\circ} \mathrm{C}$ and fully hematite at $800^{\circ} \mathrm{C}$. The small peak detected at $2 \theta=29.7^{\circ}$ from the raw as well as thermally treated up to $500{ }^{\circ} \mathrm{C}$ is due to the impurities of $\mathrm{CaSO}_{4} \cdot 0.5 \mathrm{H}_{2} \mathrm{O}$ which were precipitated in situ in the effluent treatment [36]. Based on the $\mathrm{Fe}-\mathrm{O}$ thermodynamic stability for different iron oxide 
phases, within the temperature range where the particular phase of the material is stable, an increase in temperature increases the particle size due to agglomeration. But, across the phase transformation temperature, the recrystallization of the lattice atoms into a different structure happens with increasing temperature which leads to the formation of a different phase of the material. When crystal growth begins an assembly of primary particles that have grown together form agglomerates that later converted into a new larger particle (aggregate). Based on the XRD data, the crystallite size of hematite nanoparticle was calculated using the two most intense peaks and found to be about $30.4 \mathrm{~nm}$ at $800{ }^{\circ} \mathrm{C}$ and $28.3 \mathrm{~nm}$ at $500{ }^{\circ} \mathrm{C}$ using the Debye Scherer equation as shown in Eq. 2.

$\mathrm{D}=\left(\frac{0.9 \lambda}{\beta \cos \theta}\right)$
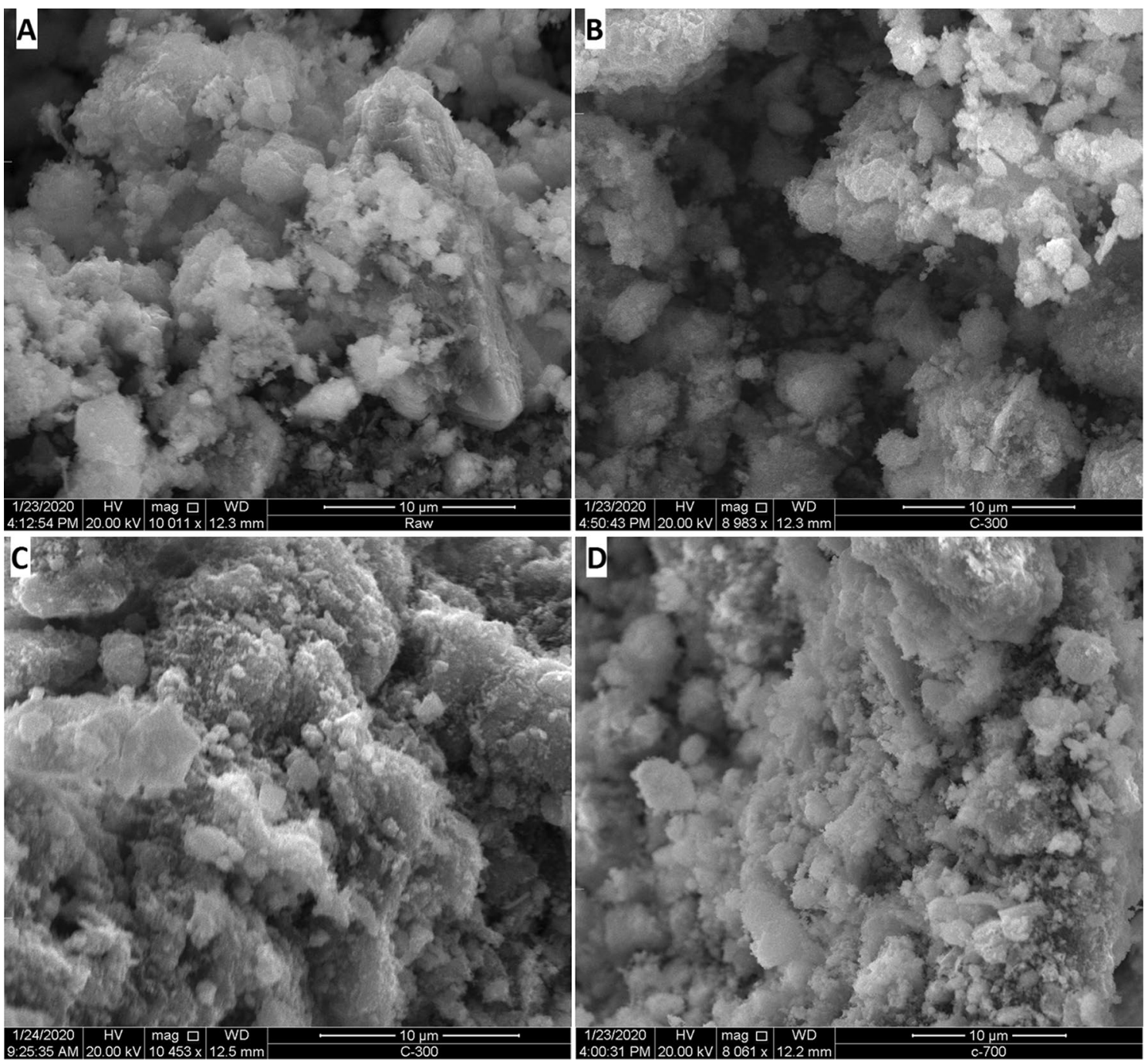

Fig. 3 SEM Micrographs of a raw, b heat-treated at $300^{\circ} \mathrm{C}$ c heat-treated at $500^{\circ} \mathrm{C}$ and $\mathbf{d}$ heat-treated at $800^{\circ} \mathrm{C}$ electro-coagulated sludge 
make a study of relationships between physicochemical parameters and chemical reactivity of iron oxide particles $[31,40]$. Though XRD is a bulk analysis technique, it confirms us that hematite, maghemite, magnetite, and goethite were the only products detected for the thermally treated samples at $800{ }^{\circ} \mathrm{C}, 500{ }^{\circ} \mathrm{C}, 300{ }^{\circ} \mathrm{C}, 100{ }^{\circ} \mathrm{C}$, and raw $\mathrm{EC}$ sludge which suggests that metal oxide impurity phases are negligible. In addition, the absence of heavy metal cation impurities is suggested based on the unavailability of XRD and FTIR peak shift caused by lattice expansion/contraction and vibrations as a result of different size cation impurity doping.

\subsection{Surface morphologies}

The scanning electron microscope, SEM, was also used to monitor the modifications in the sample morphology of raw and thermally treated electro-coagulated sludge. The raw and thermally treated electro-coagulated sludge resulted in a significant structural transformation are shown in Fig. 3a-d. The powered sludge is unstructured in nature, irregular in shape with uneven edge agglomerate and rough in the surface. Adsorptive and rough surface is observed, filling with many small grains of other iron oxides such as maghemite and hematite [41], and formed a complex structure. There is a notable difference in the micrographs obtained for both raw and thermally treated at $300^{\circ} \mathrm{C}$ which are observed less rough than the samples treated at higher temperatures $\left(500\right.$ and $800^{\circ} \mathrm{C}$ ) with a distinguishing appearance, characteristic of sintered material. High temperature treated samples (Fig. 3c, d) produced materials with more rough indicating better adsorptive nature compared to the raw and $300^{\circ} \mathrm{C}$ treated sludge. This roughness could provide better adsorption property for high temperature treated samples. It suggests that removing the dissolved solids and organic contaminants from the matrix sludge resulted in more adsorptive, porous crystalline morphology of heat-treated but are amorphous morphology in the raw EC sludge. This is also confirmed with XRD diffraction patterns. It can be noticed that the oxidative transformation of iron hydroxide/oxyhydroxide and ferrite containing electro-coagulated sludge to maghemite and hematite through subsequent temperature. From the electro-coagulated metal hydroxide sludge, different elements detected and dominantly were iron about $83 \%$ as reported by Adyel et al. [42], out of the twentytwo elements that have been executed. It is aggregates, dispersive aggregates corresponding to the top surface layer of the powdered EC sludge products. Similar morphological structures of iron hydroxides and iron oxides were reported $[34,43,44]$.

\subsection{UV absorption}

From the scattering theory, the shape of the spectra and wavelength of the maximum optical extermination depends on the dielectric function of the nanoparticles [45]. Due to the interaction of liquid molecules and charged nanoparticles in the media, electrical layers surround the surface of generated nanoparticles which makes the spectral pattern different [46]. Besides, due to having high dipole moment in liquid solvent sufficient electrostatic repulsive force occurs because of the overlying of a strong electrical layer. A similar report on zinc oxide nanoparticles with the effect of solvents, such as acetone, ethanol, and water for their optical and morphological properties has been reported [47]. Due to these problems, it is better to measure the diffuse reflectance spectra of solid samples than their liquid dispersion. Hence, the UV-Vis diffuse reflectance spectra of the electro-coagulated sludge material in the wavelength of $400-700 \mathrm{~nm}$ have been measured. The UV-visible spectra of solid raw and thermally treated electro-coagulated sludge were determined as shown in Fig. 4a. The diffuse reflectance spectra of samples treated at 300,500 and $800^{\circ} \mathrm{C}$ showed an abrupt change in loss of reflectance at about $620 \mathrm{~nm}$, displaying the increased absorption of light by the material. The raw electro-coagulated sludge has not shown clear absorption onset relative to the heat treated samples. As iron electrodes are used during the electro-coagulation process, the sludge contains mixtures of iron hydroxide and oxyhydroxide. Thermal annealing of mixtures of iron hydroxide and oxyhydroxide produces different phases of iron oxide depending on the annealing temperature. This is confirmed from the XRD measurement. Pure a- $\mathrm{Fe}_{2} \mathrm{O}_{3}$ phases and $800{ }^{\circ} \mathrm{C}$ and mixture of $\mathrm{a}-\mathrm{Fe}_{2} \mathrm{O}_{3}$ and $\boldsymbol{\gamma}-\mathrm{Fe}_{2} \mathrm{O}_{3}$ were formed at $800^{\circ} \mathrm{C}$ and $500^{\circ} \mathrm{C}$, respectively.

The optical bandgap of the synthesized samples was calculated from diffuse reflectance spectra using Tauc plot method and Kubelka-Munk model.

$F(R)=\frac{(1-R)^{2}}{2 R}$

$(F(R) \mathrm{hv})^{\mathrm{n}}=\mathrm{k}(\mathrm{hv}-\mathrm{Eg})$

where $F(R)$ represents the Kubelka-Munk function, Eg is the bandgap energy, hv is the photon energy, $R$ is reflectance and $\mathrm{k}$ is a constant [48]. The optical band gap was found to be $2.06,1.98$, and $2.00 \mathrm{eV}$ for $300^{\circ} \mathrm{C}, 500^{\circ} \mathrm{C}$, and $800^{\circ} \mathrm{C}$ heat-treated samples respectively as shown in Fig. $4 \mathrm{~b}-\mathrm{d}$. The bandgap values of hematite, maghemite, and magnetite found in this work are in good agreement with previous works [49]. 

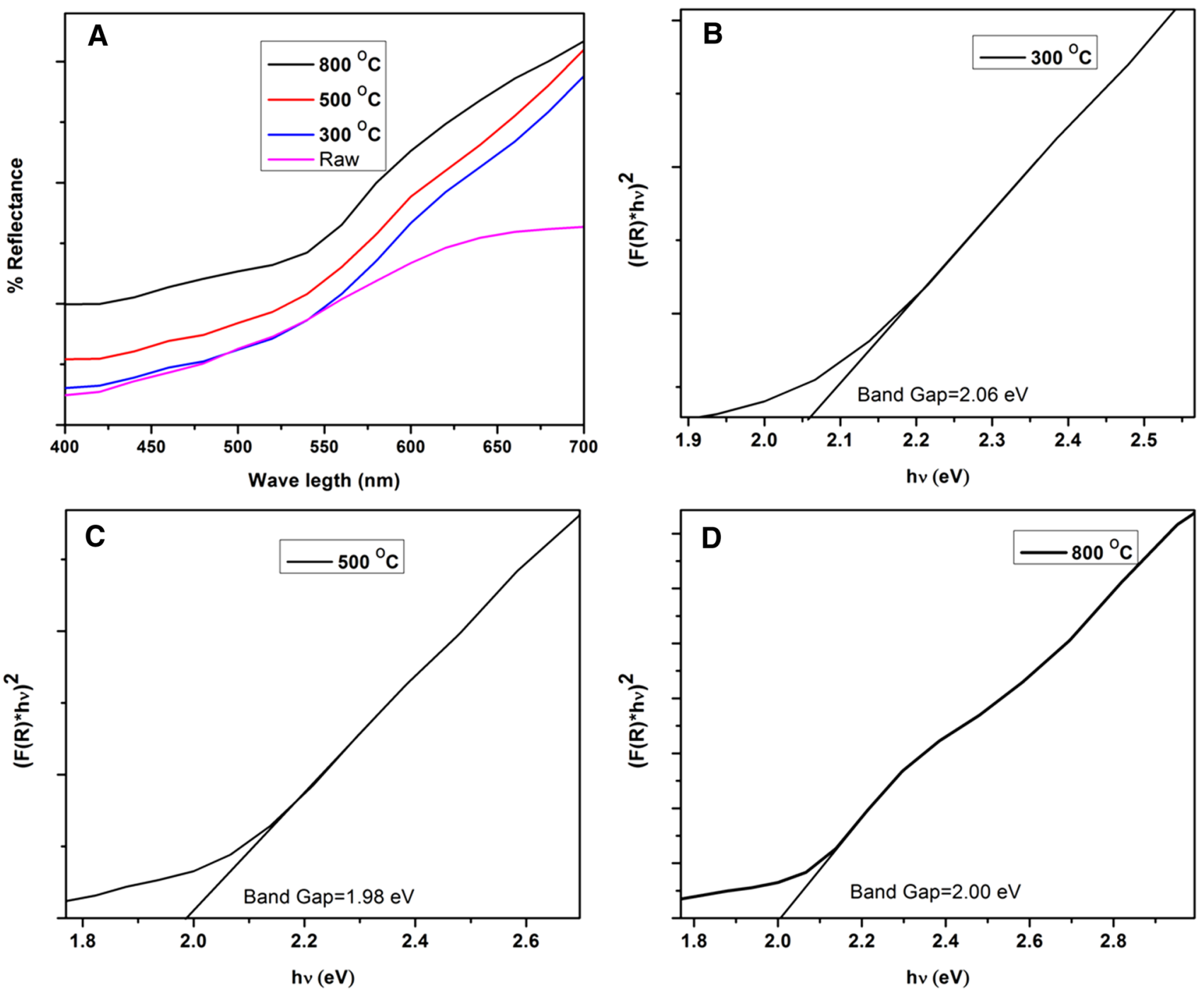

Fig. 4 UV-Vis diffuse reflectance spectra (a) and $[\mathrm{F}(\mathrm{R}) \mathrm{hv}]^{2}$ versus hv plot of electro-coagulated sludge thermally annealed at $300{ }^{\circ} \mathrm{C}(\mathbf{b})$, $500^{\circ} \mathrm{C}(\mathbf{c})$, and $800^{\circ} \mathrm{C}(\mathbf{d})$

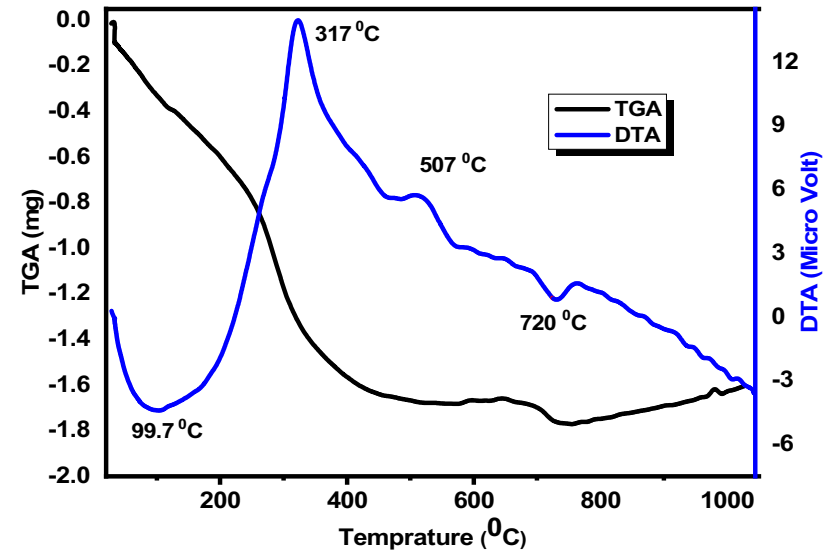

Fig. 5 Thermogravimetric analysis (TGA) and differential thermal analysis (DTA) of raw electro-coagulated sludge

\subsection{Thermogravimeteric analysis}

The thermogravimetric analysis (TGA) versus differential thermal analysis (DTA) for purified through beneficiation electro-coagulated sludge was determined as shown in Fig. 5. The surface and absorbed water removal was observed from the TGA curves approximately up to 99.7, and extend to $248{ }^{\circ} \mathrm{C}$, respectively. This accounts for $0.78 \mathrm{mg}$ weight losses. Correspondingly, the endothermic peak has occurred around $99.7^{\circ} \mathrm{C}$ which is a result of evaporation of the bonded water molecules from the EC sludge. A dramatic weight loss, around $0.92 \mathrm{mg}$, was observed from 250 to $580^{\circ} \mathrm{C}$ suggests that the dehydroxylation processes. The results indicated that high weight loss occurred in two steps, the first at around up to $248^{\circ} \mathrm{C}$. The second weight loss up to $580^{\circ} \mathrm{C}$, is associated with 


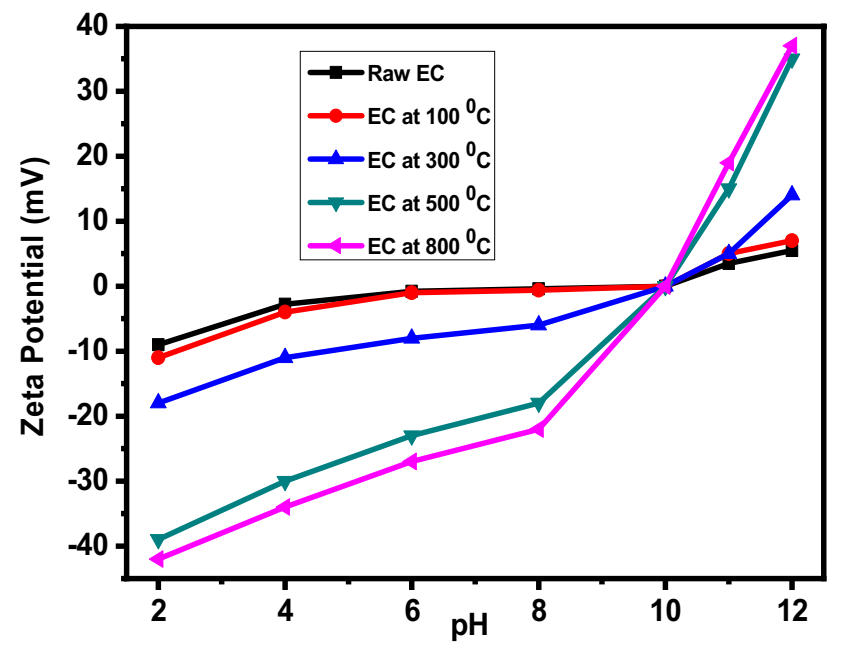

Fig. 6 Zeta potential versus $\mathrm{pH}$ ionic activity of solution for raw and thermally treated $\left(100-800^{\circ} \mathrm{C}\right)$ EC sludge

the structural hydroxyl content $(-\mathrm{OH})[50,51]$. The differential thermal analysis (DTA) shown that the sharp exothermic peak around $317^{\circ} \mathrm{C}$ which is the result of the oxidative transformation of $\mathrm{Fe}_{3} \mathrm{O}_{4}$ to $\gamma$ - $\mathrm{Fe}_{2} \mathrm{O}_{3}$; expected in the temperature range of $200-400^{\circ} \mathrm{C}$ [52]. Also, the small exothermic peak around $507^{\circ} \mathrm{C}$ accounts for the phase transformation from $\gamma-\mathrm{Fe}_{2} \mathrm{O}_{3}$ to $a-\mathrm{Fe}_{2} \mathrm{O}_{3}$. Differential thermal analysis (DTA) results are associated with the mass loss of water, organic contaminant, and structural $-\mathrm{OH}$ as in the TGA and also with phase transformation [41]. It can be deduced that it by varying the temperature different form of iron oxides can be produced. With increasing temperature, the oxidative transformation favors magnetite/maghemite toward hematite formation. The total weight loss of raw electro-coagulated sludge determined by thermogravimetric analysis (TGA) in the temperature range of $99.7-580^{\circ} \mathrm{C}$ was $1.7 \mathrm{mg}$ out of $15 \mathrm{mg}$ which is $11.33 \%$ losses. From this much of losses, it can be deduced that decomposable organic pollutants from the sludge are insignificant suggesting the iron hydroxide and oxyhydroxide flocs have been produced during the electrocoagulation treatment process.

\subsection{Zeta potentials}

The nanostructure materials having a magnetic nature can affect the interfacial electrical characteristics for different uses; such as photocatalytic application at the solid-liquid electrolyte interface, and the surface electric charge. Thus, electrophoretic mobility can be assessed by electrokinetic measurements [53]. The electrokinetic behavior of electrocoagulated sludge in acidic and basic solution was investigated and the zeta potential was examined. As shown in Fig. 6 zeta potential-pH curve for the raw and thermally treated $\left(100,300,500\right.$, and $\left.800^{\circ} \mathrm{C}\right) \mathrm{EC}$ sludge with a range of solution $\mathrm{pH}$. The point of zero charges occurs at a $\mathrm{pH}$ of 10 and a range of zeta potentials was recorded with -42 to $39 \mathrm{mV}$. These results indicate that the material may agglomerate and have an excellent adsorptive feature [54].

As the $\mathrm{pH}$ increase, raw and thermally treated EC sludge expected to have more hydroxyl groups charged surface which favors the more positive zeta potential values. Thermally treated EC sludge has high zeta potential value as compared with the raw EC sludge. The highest zeta potential is achieved in a thermally treated EC sludge at $800^{\circ} \mathrm{C}$ due to the raw EC sludge has different impurities from the textile effluent which can shield the electrostatic interaction. Also, the maghemite and hematite nanoparticles have not existed before thermal treatments. This is also confirmed with XRD diffraction patterns and SEM micrographs.

\section{Conclusion}

The wet textile factory is treating its effluent with electrocoagulation process but the amount of sludge produced by wastewater treatment plants is increased and its accumulation is a burden to the factory. This can affect the environment adversely and the need for effective reuse of the sludge becomes a vital issue in the world. Thus, the study reports a promising way of recycling mechanisms of sludge into valuable iron oxides which can be used for industrial, commercial, and medical purposes. Materials characterization by XRD suggests that iron oxide nanoparticles are contained dominantly and its microstructure was observed. FTIR and XRD confirmed that iron hydroxide disappeared after heat treatment which tells that transformation of iron hydroxide to maghemite and hematite have occurred. It can be deduced that iron oxide nanoparticles can be recycled from wastewater sludge having electrochemical processes in their effluent treatment plant for different applications, such as for water and wastewater treatment, for printing machine industrial and medical uses. Utilizations of sludge from the electrochemical processes of wastewater treatment are a good opportunity for different commercial and industrial applications as well as waste management for a sustainable environment. Also, this research findings can have a potential to industrialists and environmentalists to think over in such a way that controlled sludge recycling mechanisms during wastewater treatment is beneficial in terms of cost and sustainability. Furthermore, an integrated wastewater treatment system with resource recycling technology at the initial stage of the installation becomes an important issue to consider. 
Acknowledgements The authors would like to thank Bahir Dar Institute of Technology, Bahir Dar University to do this research opportunity. Also, my thanks go to the GIZ STEPS program collaboratively with Bahir Dar Institute of Technology university-industry linkage office.

Author contributions TAA has designed the research, experiment, wrote original manuscript, conceptualized and reviewed and Dr. BAA has undergone UV-Vis spectra, XRD and SEM data interpretation and scientific discussion.

Funding This research have not funded but done in our university laboratories with existing facilities.

\section{Compliance with ethical standards}

Conflict of interest The author declares that they have no known competing for financial interests or personal relationships that could have appeared to influence the work reported in this work.

\section{References}

1. Ghanbari F, Moradi M, Eslami A et al (2014) Electrocoagulation/ flotation of textile wastewater with simultaneous application of aluminum and iron as anode. Environ Process 1:447-457

2. Verma AK (2017) Treatment of textile wastewaters by electrocoagulation employing $\mathrm{Fe}-\mathrm{Al}$ composite electrode. J Water Process Eng 20:168-172

3. Mahmad MKN, Rozainy MAZMR, Abustan I et al (2016) Electrocoagulation process by using aluminium and stainless steel electrodes to treat total chromium. Colour Turbid Procedia Chem 19:681-686

4. Safari S, Azadi Aghdam M, Kariminia HR (2016) Electrocoagulation for COD and diesel removal from oily wastewater. Int J Environ Sci Technol 13:231-242

5. Parga JR, Cocke DL, Valverde V et al (2005) Characterization of electrocoagulation for removal of chromium and arsenic. Chem Eng Technol 28:605-612

6. Gomes JAG, Daida P, Kesmez M et al (2007) Arsenic removal by electrocoagulation using combined Al-Fe electrode system and characterization of products. J Hazard Mater 139:220-231

7. Balek V, Šubrt J (1995) Thermal behaviour of iron(III) oxide hydroxides. Pure Appl Chem 67:1839-1842

8. Cuenca JA, Bugler K, Taylor S et al (2016) Study of the magnetite to maghemite transition using microwave permittivity and permeability measurements. J Phys Condens Matter 28:106002

9. Liu XM, Shaw J, Jiang JZ et al (2010) Analysis on variety and characteristics of maghemite. Sci China Earth Sci 53:1153-1162

10. Kalska-Szostko B, Wykowska U, Satula D et al (2015) Thermal treatment of magnetite nanoparticles. Beilstein J Nanotechnol 6:1385-1396

11. Teja AS, Koh PY (2009) Synthesis, properties, and applications of magnetic iron oxide nanoparticles. Prog Cryst Growth Charact Mater 55:22-45

12. Shokrollahi H (2017) A review of the magnetic properties, synthesis methods and applications of maghemite. J Magn Magn Mater 426:74-81

13. Cotin G, Piant S, Mertz D et al (2018) Iron oxide nanoparticles for biomedical applications: synthesis, functionalization, and application. In: Korotcenkov G (ed) Iron oxide nanoparticles biomedical applications. Elsevier, Amsterdam, pp 43-88
14. Chirita M, Grozescu I (2009) $\mathrm{Fe}_{2} \mathrm{O}_{3}$-nanoparticles, physical properties and their photochemical and photoelectrochemical applications. Chem Bull 54:1-8

15. Björkstén U, Moser J, Grätzel M (1994) Photoelectrochemical studies on nanocrystalline hematite films. Chem Mater 6:858-863

16. Sivula K, Zboril R, Le Formal F et al (2010) Photoelectrochemical water splitting with mesoporous hematite prepared by a solution-based colloidal approach. J Am Chem Soc 132:7436-7444

17. Zhai T, Yao J (2012) One-dimensional nanostructures: principles and applications. Wiley, Hoboken

18. Lompe KM, Menard D, Barbeau B (2017) The influence of iron oxide nanoparticles upon the adsorption of organic matter on magnetic powdered activated carbon. Water Res 123:30-39

19. Aragaw TA (2020) Recovery of Iron hydroxides from electrocoagulated Sludge for adsorption removals of dye wastewater: adsorption capacity and adsorbent characteristics. Surf Interfaces 18:100439

20. Mousavi SM, Hashemi SA, Esmaeili $\mathrm{H}$ et al (2018) Synthesis of $\mathrm{Fe}_{3} \mathrm{O}_{4}$ nanoparticles modified by oak shell for treatment of wastewater containing $\mathrm{Ni}(\mathrm{II})$. Acta Chim Slov 65:750-764

21. Moreno CHA, Cocke DL, Gromes JA et al (2009) Electrochemical reactions for electrocoagulation using iron electrodes. Ind Eng Chem Res 48:2275-2282

22. Kim DG, Palacios RJS, Ko SO (2014) Characterization of sludge generated by electrocoagulation for the removal of heavy metals. Desalin Water Treat 52:909-919

23. Hunter RJ (1981) Zeta potential in colloid science: principles and applications. Academic Press, London

24. Farahmandjou M, Soflaee F (2015) Synthesis and characterization of $\mathrm{a}-\mathrm{Fe}_{2} \mathrm{O}_{3}$ nanoparticles by simple co-precipitation method. Phys Chem Res 3:191-196

25. Feng $L$, Zheng $H$, Gao B et al (2017) Fabricating an anionic polyacrylamide (APAM) with an anionic block structure for high turbidity water separation and purification. RSC Adv 7:28918-28930

26. Liang S, Guo X, Tian Q (2011) Adsorption of $\mathrm{Pb}^{2+}$ and $\mathrm{Zn}^{2+}$ from aqueous solutions by sulfured orange peel. Desalination 275:212-216

27. Mohammed IA, Mustapha A (2010) Synthesis of new azo compounds based on n-(4-hydroxypheneyl) maleimide and n-(4-methylpheneyl) maleimide. Molecules 15:7498-7508

28. Ogunmodede OT, Ojo AA, Adewole E et al (2015) Adsorptive removal of anionic dye from aqueous solutions by mixture of Kaolin and bentonite clay: characteristics, isotherm, kinetic and thermodynamic studies. Iran J Energy Environ 6:147-153

29. Chahal S, Kumar A et al (2020) $\mathrm{Zn}$ doped a- $\mathrm{Fe}_{2} \mathrm{O}_{3}$ : an efficient material for UV driven photocatalysis and electrical conductivity. Crystals 10:273

30. Jansi Rani B, Mageswari R, Ravi G et al (2017) Design, fabrication, and characterization of hematite $\left(\mathrm{a}-\mathrm{Fe}_{2} \mathrm{O}_{3}\right)$ nanostructures. JOM 69:2508-2514

31. Chernyshova IV, Hochella MF, Madden AS (2007) Size-dependent structural transformations of hematite nanoparticles. 1. Phase transition. Phys Chem Chem Phys 9:1736-1750

32. Mohammed KA, Al-Rawas AD, Gismelseed AM et al (2012) Infrared and structural studies of $\mathrm{Mg}_{1-\mathrm{x}} \mathrm{Zn}_{\mathrm{x}} \mathrm{Fe}_{2} \mathrm{O}_{4}$ ferrites. Phys $\mathrm{B}$ Condens Matter 407:795-804

33. Chen R, Chai L, Li Q et al (2013) Preparation and characterization of magnetic $\mathrm{Fe}_{3} \mathrm{O}_{4} / \mathrm{CNT}$ nanoparticles by RPO method to enhance the efficient removal of $\mathrm{Cr}(\mathrm{VI})$. Environ Sci Pollut Res 20:7175-7185

34. Castañeda-DÍaz J, Pavón-Silva T, Gutiérrez-Segura E et al (2017) Electrocoagulation-adsorption to remove anionic and cationic dyes from aqueous solution by PV-energy. J Chem 14:2017 
35. Ovcharenko R, Voloshina E, Sauer J (2016) Water adsorption and O-defect formation on $\mathrm{Fe}_{2} \mathrm{O}_{3}(0001)$ surfaces. Phys Chem Chem Phys 18:25560-25568

36. Flores RG, Andersen SLF, Maia LKK et al (2012) Recovery of iron oxides from acid mine drainage and their application as adsorbent or catalyst. J Environ Manag 111:53-60

37. Cho W, Park S, Oh M (2011) Coordination polymer nanorods of Fe-MIL-88B and their utilization for selective preparation of hematite and magnetite nanorods. Chem Commun 47:4138-4140

38. Basavegowda N, Somai Magar KB, Mishra K et al (2014) Green fabrication of ferromagnetic $\mathrm{Fe}_{3} \mathrm{O}_{4}$ nanoparticles and their novel catalytic applications for the synthesis of biologically interesting benzoxazinone and benzthioxazinone derivatives. New J Chem 38:5415-5420

39. Fernández-García M, Martínez-Arias A, Hanson JC et al (2004) Nanostructured oxides in chemistry: characterization and properties. Chem Rev 104:4063-4104

40. Mazeina L, Deore S, Navrotsky A (2006) Energetics of bulk and nano-akaganeite, $\beta-\mathrm{FeOOH}$ : enthalpy of formation, surface enthalpy, and enthalpy of water adsorption. Chem Mater 18:1830-1838

41. Kashyap S, Sklute EC, Dyar MD et al (2018) Reduction and morphological transformation of synthetic nanophase iron oxide minerals by hyperthermophilic archaea. Front Microbiol 9:1550

42. Adyel TM, Rahman SH, Zaman MM et al (2013) Reuse feasibility of electrocoagulated metal hydroxide sludge of textile industry in the manufacturing of building blocks. J Waste Manag 9:2013

43. Nguyen KM, Nguyen BQ, Nguyen HT et al (2019) Adsorption of arsenic and heavy metals from solutions by unmodified iron-ore sludge. Appl Sci 9:619

44. Baltazar SE, García A, Romero AH et al (2014) Surface rearrangement of nanoscale zerovalent iron: the role of $\mathrm{pH}$ and its implications in the kinetics of arsenate sorption. Environ Technol 35:2365-2372

45. Dadashi S, Poursalehi R, Delavari H (2015) Structural and optical properties of pure iron and iron oxide nanoparticles prepared via pulsed Nd:YAG laser ablation in liquid. Procedia Mater Sci 11:722-726

46. Venkatesham M, Ayodhya D, Madhusudhan A et al (2014) A novel green one-step synthesis of silver nanoparticles using chitosan: catalytic activity and antimicrobial studies. Appl Nanosci 4:113-119

47. Khoza PB, Moloto MJ, Sikhwivhilu LM (2012) The effect of solvents, acetone, water, and ethanol, on the morphological and optical properties of $\mathrm{ZnO}$ nanoparticles prepared by microwave. J Nanotechnol 6:2012

48. Tauc J (1968) Optical properties and electronic structure of amorphous Ge and Si. Mater Res Bull 3:37-46

49. Kurien $\mathrm{U}, \mathrm{Hu} Z$, Lee $\mathrm{H}$ et al (2017) Radiation enhanced uptake of $\mathrm{HgO}(\mathrm{g})$ on iron (oxyhydr) oxide nanoparticles. RSC Adv 7:45010-45021

50. Cornell RM, Schwertmann U (2003) The iron oxides: structure, properties, reactions, occurrences and uses, 2nd edn. Wiley, Hoboken

51. El-Sharkawy EA, El-Hakam SA, Samra SE (2000) Effect of thermal treatment on the various properties of iron(III)-aluminum(III) coprecipitated hydroxide system. Mater Lett 42:331-338

52. Horvath G, Szalay Z, Simo F et al (2019) Recycling of a wastewater to iron oxide micro structures. Environ Res Commun 1:085001

53. Reyes-Bahena JL, Robledo-Cabrera A, López-Valdivieso A et al (2002) Fluoride adsorption onto $\mathrm{a}-\mathrm{Al}_{2} \mathrm{O}_{3}$ and its effect on the zeta potential at the alumina-aqueous electrolyte interface. Sep Sci Technol 37:1973-1987

54. Kim J, Lawler DF (2005) Characteristics of zeta potential distribution in silica particles. Bull Korean Chem Soc 26:1083-1089

Publisher's Note Springer Nature remains neutral with regard to jurisdictional claims in published maps and institutional affiliations. 